\title{
El legado pedagógico de Paulo Freire: una pedagogía de la esperanza que nos inspira para transformar el mundo
}

\author{
María Verdeja Muñiz ${ }^{1}$ \\ Orcid: https://orcid.org/0000-0003-0499-9248
}

\begin{abstract}
Resumo
Paulo Reglus Neves Freire nació el 19 de septiembre de 1921 en Recife, capital del estado brasileño de Pernambuco, así pues, en septiembre del presente año 2021, nos encontramos ante el centenario de su nacimiento. Para los educadores críticos y aquellos que soñamos con cambiar y transformar el mundo en el que vivimos, significa un momento muy importante, principalmente, porque consideramos que su legado continúa vigente en nuestros días. $\mathrm{Su}$ pedagogía nos ofrece la posibilidad y la esperanza de cambiar el rumbo del mundo. Para ello es necesario transformar nuestros sistemas educativos y apostar por un modelo de enseñanza que favorezca la reflexión y pensamiento crítico tanto de estudiantes como de los docentes. Dicha tarea, necesariamente, debe ir acompañada de esperanza, sueños y utopía sin olvidar nunca que, tal transformación, aunque difícil, es posible. Freire manifestaba convencido que la educación necesita tanto de formación técnica, científica y profesional, como de sueños y utopía. Sin esperanza no es posible la transformación. Sin el sueño de una mejora colectiva no es posible la actividad transformadora.
\end{abstract}

Palavras-chave: Paulo Freire. Esperanza. Educación problematizadora. Análisis crítico, Diversidad cultural. Escuela democrática.

\begin{abstract}
Paulo Reglus Neves Freire was born on September 19, 1921, in Recife, capital of the Brazilian state of Pernambuco, thus, in September of this year 2021, we are facing the centenary of his birth. This event for critical educators and those of us who dream of changing and transforming the world in which we live, represents a very important moment, mainly because we consider that Freire's legacy continues today. His pedagogy offers us the possibility and the hope of changing the course of the world. For this, it is necessary to transform our educational systems and bet on a teaching model that favors reflection and critical thinking of both students and teachers. This task, necessarily, must be accompanied by hope, dreams, and utopia without ever forgetting that such a transformation, although difficult, is possible. Freire was convinced that education needs both technical, scientific, and professional training, as well as dreams and utopia. Without illusion, transformation is not possible. Without the dream of collective improvement, transformative activity is not possible.
\end{abstract}

Keywords: Paulo Freire. Hope. Problematizing education. Critical analysis. Cultural diversity. Democratic school.

\footnotetext{
${ }^{1}$ Licenciada y doctora en pedagogía por la Universidad de Oviedo. Actualmente trabaja como profesora Ayudante Doctora en el Departamento de Ciencias de la Educación en el Área de Didáctica y Organización Escolar. Su experiencia como profesora en la Universidad de Oviedo cubre una amplia diversidad de docencia impartida tanto en estudios de grado, máster, y doctorado. Sus principales líneas de investigación se centran en el estudio de la pedagogía y obra de Paulo Freire, los retos que plantea la educación en contextos multiculturales, la educación intercultural y la atención a la diversidad cultural del alumnado desde un enfoque de educación inclusiva y de justicia social.E-mail: verdejamaria@uniovi.es
} 


\section{Introducción}

En el año en que conmemoramos el centenario del nacimiento del educador brasileño Paulo Freire (1921-1997) es un año en el que navegamos en un mar de incertidumbres -sociales, humanitarias, políticas, educativas, sanitarias-y en el que, por momentos, el desaliento quiere apoderarse de nuestras vidas. Lejos de dejarnos atrapar por las redes de la desesperanza, nos proponemos reflexionar acerca de las cosas que podemos hacer desde el ámbito educativo para construir un mundo mejor. La pedagogía de Freire es una pedagogía de la esperanza que nos propone hacer una lectura crítica del mundo y nos brinda las posibilidades de transformar las injusticias sociales. A través del siguiente texto nos proponemos poner de manifiesto la vigencia del pensamiento y pedagogía de Freire porque consideramos que sus aportaciones tienen plena vigencia en nuestros días. Sin embargo, en ocasiones, no prestamos la suficiente atención a las reflexiones de Freire, o lo dejamos caer en el olvido... Incluso, pensamos que los retos que planteaba el autor en los lejanos años 70 han sido superados, pero, en realidad, esto no es así. Por este motivo, entendemos que es necesario re-pensar a Freire y su pedagogía dado que, sus aportaciones pueden ser de gran utilidad en nuestros días y nos pueden ofrecer posibles respuestas a determinados retos educativos del momento. Para comenzar nuestro recorrido por los postulados de su pedagogía, lo haremos de la mano de diferentes autores y autoras que lo han conocido o han tenido la oportunidade de trabajar junto a él. A Freire le interesaban ciertas temáticas que están presentes a lo largo de toda su obra. En este pequeño texto ponemos nuestra mirada en algunas de ellas porque, consideramos, son de gran interés en los contextos educativos actuales.

Es necesario comenzar diciendo que las ideas centrales del pensamiento pedagógico político de Freire y las aportaciones de su pedagogía admiten diversidad de lecturas. Es por este motivo que el educador brasileño siempre ha sido interpretado desde diferentes enfoques y perspectivas (GIROUX, 1998; LENS, 2001; TORRES, 2001; TORRES, 2004; GADOTTI, 2007, KOHAN, 2019; VERDEJA, 2020). Esa diversidad de enfoques nos brinda la oportunidad de mantener un diálogo con su obra y también nos permite acercarnos a ella con diferentes miradas.

Por otra parte, se puede decir que Freire elaboró sus propuestas pedagógicas en coherencia con las experiencias personales que le tocó vivir y en interacción con las personas que le rodearon. El propio Freire, en alguna ocasión, hace referencia a diversas lecturas que le influyeron (FREIRE, 1993 p. 17) y menciona que las principales fuentes que inspiraron sus planteamientos fueron sus lecturas, las situaciones que le tocó vivir, la interacción con las personas que le rodeaban; en definitiva: su gente cercana, su familia, sus amistades, las conversaciones con sus colegas y sus lecturas. Esto queda claro, por ejemplo, en obras como Pedagogía de la esperanza (1993) obra que, tal y como indicaba Santos-Gómez (2008), es enormemente coherente con su pedagogía pues en ella se puede observar que no hay una separación entre la vida y la teoría del educador brasileño.

Como señala Giroux (1998) su obra nos ofrece diversidad de lecturas y en ese sentido podemos observar que Paulo Freire deja tras de sí un cuerpo de trabajo construido en el transcurso de una vida de lucha y compromiso. Rechazando la comodidad de las grandes narraciones ejemplares, la obra de Freire siempre resultó inquieta e inquietante, agitada y, sin embargo, atractiva (p.3).

Para Torres (2004) poco importa si unos entendieron mejor a Freire que otros, si hubo quienes comprendieron realmente su pensamiento o no. Quizás, la contribución mayor de Freire está en haber logrado comunicarse y conectarse con mucha gente, ayudarles a saber que existe algo llamado educación y algo llamado pobreza/marginación/opresión y que existe una relación entre ellas. Esto, en definitiva, es lo que cruza su vida y confiere grandeza a su obra, su mensaje de esperanza, de lucha, de perseverancia, de no resignación, de no claudicación. Freire nos ha 
dejado un legado que es mucho mayor y duradero que cualquier teoría educativa y que cualquier método de alfabetización.

La importancia de las exigencias planteadas para los docentes la podemos encontrar en Freire (1997) donde reflexiona acerca de las orientaciones que debieran guiar la práctica. Desde una reflexión sobre su propia práctica y a través de un lenguaje accesible y didáctico, hace referencia a los saberes necesarios para la práctica educativo-crítica con base en una éticapedagógica y nos presenta una visión de la educación cimentada en el rigor, la investigación, la actitud crítica, el riesgo, la humildad, el buen juicio, la tolerancia, la alegría, la curiosidad, la competencia... y otras virtudes, todas ellas, bañadas por la esperanza.

Diversos autores (BESALÚ, 2002; POSADA, 2007; GADOTTI, 2007; SANTOSGÓMEZ, 2008) nos animan a continuar estudiando su obra, no para venerarlo como se veneraría a un tótem, ni para seguirlo como a un gurú, sino para leerlo como a uno de los más grandes educadores críticos del siglo XX. Honrar a un autor es, sobre todo, estudiarlo y revisarlo de manera crítica, retomar sus temas, sus problemas, sus cuestionamientos:

Paulo retomaba con frecuencia los mismos temas. Hay algo que permanece constante en su pensamiento: su preocupación ética, su compromiso con los "condenados de la tierra" (Pedagogía del oprimido), con los "excluidos" (Pedagogía de la autonomía). Su punto de vista siempre fue el mismo. Lo diferencia es el énfasis en ciertas problemáticas que, estas sí, se van diversificando y evolucionando (GADOTTI, 2007, p. 86).

Gadotti (2007) nos recuerda a un Paulo Freire que estaba escribiendo su último libro: "ética del género humano", apuntando hacia el sueño posible de una humanidad unida en torno a un objetivo común de justicia, paz y prosperidad para todos. Ese es el sueño. Se trata de hacer que sea viable históricamente: "El poder de la obra de Paulo Freire no está tanto en su teoría del conocimiento, sino en el hecho de haber insistido en la idea de que es posible, urgente y necesario cambiar el orden de las cosas" (p. 89). Queremos recordar como dice Gadotti (2007) que Pedagogía del Oprimido nació de las luchas utópicas de los años 60 pero sus aportaciones continúan de actualidad:

Por ello, este libro de Paulo Freire sigue siendo tan actual y lo seguirá siendo en la medida que haya oprimidos. Lo que plantea el libro aún no ha sucedido. No se puede dar por superada una pedagogía del oprimido mientras existan oprimidos. No se puede superar la lucha de clases mientras existan privilegios de clase (p. 33).

Tomando como referencia a Santos-Gómez (2008) quien, con brillantez, ha desarrollado la compleja tarea de indagar acerca de las ideas filosóficas que fundamentan el pensamiento de Freire, nos quedamos con esta reflexión porque consideramos que explica con gran sencillez y claridad algunas influencias y pensamientos del autor que están en coherencia con los argumentos que venimos exponiendo pero, sobre todo, nos parece interesante porque representa, con una gran claridad, la vigencia de su pensamiento:

He señalado que la pedagogía del oprimido de Paulo Freire supone una síntesis de importantes corrientes filosóficas del siglo XX aplicadas al quehacer educativo; pero, sobre todo, deseo destacar que, si bien es cierto que la pedagogía del oprimido encaja, lógicamente, con la realidad del Tercer Mundo y en ella encuentra su eco y razón de ser, creo que, si el 
Tercer Mundo es un producto del primero y ambos mundos se relacionan como dos caras de una misma moneda, Freire tiene pleno sentido universal (...). El pedagogo brasileño nos enseña que en el hecho de tomar en cuenta al otro nos va la propia vida. Sin duda, la utopía de los seres humanos colaborando, conversando y, sobre todo, escuchándose, está llena de sentido y vigencia (p. 171).

Para otros autores (FLECHA, 1997) una de las cuestiones más interesantes es la crítica que Freire siempre hizo al neoliberalismo. El problema de los conservadores no solo se manifestaba en que consideraban la sociedad sin posibilidades de cambio sino que, el problema más grande lo representaba la falta de ilusión por la vida, así pues, Freire renegaba de expresiones conservadoras y neoliberales - que consideraba fatalistas e inmovilizantes- tales como: "las cosas son así porque no pueden ser de otra forma" dado que consideraba que eran expresiones profundamente faltas de esperanza y negacioncitas en cuanto que no permitían a las personas soñar con la construcción de un mundo mejor para todos los seres humanos:

Se oponía radicalmente al neoliberalismo, al reproduccionismo y al posmodernismo, no solo porque negaban la transformación solidaria de la realidad social, sino también porque dibujaban un mundo donde no cabían los mejores sentimientos humanos (p. 90).

\section{Algunas reflexiones sobre temáticas recurrentes en el educador brasileño}

Recordamos que a Freire le preocupaban, en especial, determinadas temáticas. Es por este motivo que a lo largo de su extensa obra retoma y profundiza en las mismas temáticas y las analiza desde diferentes perspectivas y miradas.

A continuación, a lo largo de este artículo, ofrecemos algunas reflexiones y lo hacemos en torno a temáticas que, sabemos, preocupaban al autor, así pues, en este trabajo realizamos algunas reflexiones sobre las siguientes temáticas: 1) Educación problematizadora Versus educación bancaria, 2) Necesidad de impulsar una escuela democrática y permanentemente abierta al cambio, 3) Necesidad de impulsar una lectura crítica del mundo, 4) Mensaje de esperanza: a pesar de que el cambio es difícil, es posible, y 5) La educación no lo puede cambiar todo, pero, algo puede hacer.

\section{Educación problematizadora Versus Educación bancaria}

La crítica que realiza Freire a la educación bancaria es una constante en toda su obra, pero, es quizás en Pedagogía del oprimido (1970) donde encontramos el mayor referente y soporte. Utiliza este término, "bancaria", para referirse a las concepciones y prácticas opresoras que se dan tanto en la escuela como en el contexto social y político: "De este modo, la educación se transforma en un acto de depositar en el cual los educandos son depositarios y el educador quien deposita" (p. 72). La propuesta de Freire parte de una educación problematizadora que niega el sistema unidireccional propuesto por la Educación bancaria y plantea una apuesta firme por una comunicación de ida y vuelta en la que ambos (educadores y educandos) se educan. Se establece un diálogo en el cual tiene lugar el proceso educativo (Kaplún, 1998).

Como alternativa Freire propone lo él denomina educación problematizadora, centrada en el análisis crítico de temáticas sociales donde educadores y educandos se convierten en sujetos activos en el proceso de construcción de conocimiento, utilizando el diálogo como método orientado a satisfacer la curiosidad profunda tanto de estudiantes como de los docentes. 
Desde la concepción de la educación problematizadora propuesta por Freire se entiende que los educandos son sujetos activos y se encuentran en proceso de construcción de la historia:

Es así como, mientras la práctica "bancaria", como enfatizáramos, implica una especie de anestésico, inhibiendo el poder creador de los educandos, la educación problematizadora, de carácter automáticamente reflexivo, implica un acto permanente de desvelamiento de la realidad. La primera pretende mantener la inmersión, al segunda, por el contrario, busca la emersión de la conciencias, de la que resulta su inserción crítica en la realidad (FREIRE, 1970, p. 86).

En relación con esta cuestión Besalú (2002) señala que, frente al discurso de la reproducción teóricamente defectuoso y estratégicamente paralizador se alza el discurso de la construcción de conocimiento que habla de la pedagogía como praxis política y ética, siendo Freire uno de los que mejor ha explicado esta posición en obras como Pedagogía de la autonomía (1997).

Freire (1994) considera que la educación, más allá de convertirse en un mero acto de reproducción de conocimientos, debe permitir a los estudiantes leer y enfrentarse a nuevos desafíos, que les permitan reflexionar sobre problemáticas y situaciones reales: "El objetivo no debería consistir en describir algo que tendrá que memorizarse. Por el contrario, sería conveniente que los textos "problematizaran" situaciones, afrontando el desafío que la realidad ofrece cotidianamente a los educandos" (p. 46).

Para Freire la educación es diálogo. Con relación a la dimensión dialógica de la educación podemos señalar que, según Lens (2001), está enraizada en la posición humanista y ético-democrática de Freire. De esta forma debemos entender la dimensión dialógica como un recurso metodológico necesario para construir una verdadera democracia, tanto en las relaciones intersubjetivas y pedagógicas cuanto en las políticas (LENS, 2001). También cabe señalar que la dialoguicidad de la educación no significa, como algunos críticos sugirieron, la igualdad de roles entre educadores y educandos. Si bien la dialoguicidad supone una relación horizontal, solo lo es en el sentido humano ya que, educadores y educandos, en tanto humanos, no son más ni menos unos que otros. Esta dialoguicidad no anula el carácter directivo de la educación pero dicha conducción debe ser democrática (LENS, 2001).

\section{Necesidad de impulsar una escuela democrática y permanentemente abierta al cambio}

Sí, como apunta Besalú (2002), la historia es posibilidad, sí la pedagogía es una práctica política, cabe hacerse algunas preguntas: ¿Qué podemos hacer desde las escuelas? Reflexionando en torno a esta cuestión podemos decir que, desde la perspectiva de Freire (1997) la primera tarea del educador es la de ayudar a entender el mundo, a conocer las cosas por su verdadero nombre, a desentrañar una representación de la realidad parcial e interesada. La segunda es ayudar a tomar posición a los educandos, desarrollar en ellos/as aptitudes y actitudes para su participación en la vida social, porque todos somos responsables de lo que pasa en el mundo y entre todos podemos cambiar las cosas.

Esto implicaría que las escuelas se conviertan en espacios de intercambio de aprendizajes y de experiencias en las que tanto estudiantes como docentes puedan reflexionar en torno a problemáticas actuales, por ejemplo: las causas de la inmigración, visualizar la pobreza y analizar las causas de diferencias entre los países ricos y pobres, identificar los problemas medioambientales y analizar sus causas, visualizar la violencia que se ejerce hacia las mujeres y denunciar los abusos a los que son sometidas miles de mujeres en todo el mundo, problematizar acerca de situaciones e injusticias que atentan contra los derechos humanos, etc. Por tanto, es necesario hacerse preguntas acerca de las cosas que suceden a nuestro alrededor. 
Sin embargo, esta es una realidad que todavía está lejos de alcanzarse, entre otras cuestiones, por el etnocentrismo y los saberes que se transmiten en la escuela. La invasión cultural (FREIRE, 1970) entronca, a nuestro modo de ver, con una visión etnocentrista de la cultura y supone uno de los principales motivos por los que Freire hace una dura crítica a lo que él denomina cultura dominante, siendo en primera instancia la escuela -aunque también se hace a través de otros ámbitos- uno de los principales reproductores de dicha cultura dominante, principalmente, a través del currículo - explícito y oculto- y también de sus contenidos.

La sociedad del siglo XXI es esencialmente multicultural y, sin embargo, las diferentes culturas no tienen las mismas posibilidades de supervivencia o de expresión en el mundo moderno. En un contexto de conflicto político y en entornos constantemente variables, las sociedades evolucionan y se adaptan, algunas son más abiertas al cambio, lo que puede dejar a las otras, especialmente las culturas minoritarias, expuestas a la pérdida y el empobrecimiento. Sus valores y estructuras pueden debilitarse a medida que entran en un mundo más globalizado (UNESCO, 2006). Sin embargo, normalmente, los currículos escolares muestran contenidos, conceptos, eventos y situaciones desde la perspectiva de la cultura dominante (FREIRE, 1970, 1993, 1994; GIROUX, 1990, FERNÁNDEZ ENGUITA, 2001) dejando al margen las experiencias de los grupos minoritarios y por eso Freire (1993, p. 105) matiza: "El problema fundamental, de naturaleza política, está coloreado por tintes ideológicos, a saber, quien elige los contenidos, a favor de quien y de qué estará su enseñanza, contra quién, a favor de qué, contra qué".

Torres Santomé (2008), en coherencia con los planteamientos de Freire, hace referencia a que la curiosidad es la clave del pensar y, por tanto, es preciso reivindicar la no indiferencia ante el otro o impedir el olvido del otro. Hay que reivindicar un espacio en el que estar juntos, en el que pueda hacerse realidad el derecho a la diferencia, pero nunca la diferencia de derechos. Así pues, en una escuela multicultural, como lo son las escuelas actuales, una de las cuestiones que a nuestro entender fundamental, está relacionada con la necesidad de evolucionar hacia un modelo de currículo menos sesgado culturalmente y en el que tenga cabida la diversidad cultural del alumnado, con todo lo que ello implica (PÉREZ TAPIAS, 2010).

Plantearse el tema de la justicia social y la igualdad de oportunidades en el sistema educativo, recuerda Torres Santomé (2008), pasa por analizar y evaluar el grado en que el currículo escolar es respetuoso con las distintas idiosincrasias de los colectivos y personas que tienen que convivir en esa institución. Sin embargo, en la actualidad los currículos escolares muestran contenidos, conceptos y situaciones desde la perspectiva de la cultura dominante (Freire, 1993; Torres Santomé, 2011) dejando al margen las experiencias de grupos minoritarios. Esta desorientación, dice Torres Santomé (2008), se pone de manifiesto cada vez con más facilidad en la medida en que, día a día, hay mayor diversidad de estudiantes en las aulas y ni los currículos obligatorios, ni los materiales curriculares los toman en consideración. Sin embargo, tal diversidad, no encaja nada bien en unas instituciones escolares pensadas para uniformizar y para imponer un canon cultural que pocas personas cuestionan, porque, como señala Torres Santomé (2008) tampoco desde las administraciones educativas se estimula este tipo de debate. La escuela y la diversidad presente en las aulas nos dan la oportunidad de aprender del contexto que nos rodea.

\section{Necesidad de impulsar una lectura crítica del mundo}

Otra de las temáticas que, quizás, más le preocupaban al educador brasileño tiene que ver con la necesidad de impulsar una lectura crítica del mundo. Así pues, una de las ideas que postulaba Freire, tiene que ver con la necesidad de "alfabetización" de la población en general, entendida ésta, como un aprendizaje necesario para toda la ciudadanía orientado a "saber leer e interpretar críticamente el mundo en el que vivimos". Esto, metafóricamente hablando, 
representaría una campaña de alfabetización de adultos y es, al mismo tiempo, un tema pendiente (VERDEJA Y GONZÁLEZ RIAÑO, 2018).

Freire (2010) plantea esta cuestión como una de las prioridades de la pedagogía crítica. Para ello hace hincapié en que es absolutamente necesario hacer una lectura crítica del mundo en el que la práctica pedagogía y la práctica política son indivisibles: "La lectura crítica del mundo es un quehacer pedagógico-político indivisible del quehacer político-pedagógico, es decir, de la acción política que envuelve la organización de los grupos y las clases populares para intervenir en la reinvención de la sociedad" (p. 53). Dicha lectura crítica del mundo, como señalan Rivas-Flores y Sverdlick (2019), implica un acto mucho más complejo que tomar conciencia, ya que implica asumir una posición epistemológica en el proceso de construcción de conocimiento y ello implica, a su vez, un compromiso histórico.

Para realizar dicha lectura del mundo (FREIRE, 1993, p. 107) la escuela es uno de los espacios donde podemos impulsar muchas de las reflexiones que el mundo necesita. Pero, no se trata de hacer una única lectura, lejos de ello, el educador brasileño apuesta por un modelo de escuela democrática en la que tengan cabida diferentes lecturas del mundo y señala claramente que el papel de los educadores y educadoras es precisamente ese: "El papel del educar o de la educadora progresista que no puede ni debe omitirse, al proponer su lectura del mundo, es señalar que existen otras lecturas del mundo diferentes a la suya y hasta antagónicas en ciertas ocasiones".

Si no realizamos una lectura crítica del mundo, nunca seremos conscientes de que existen desigualdades y tampoco podremos soñar con las posibilidades reales de cambio. El gran problema reside en que, tal vez, hemos "naturalizado" las desigualdades, es decir, nos acostumbramos a vivir y con ellas y, lo peor de todo: pensamos que no es posible el cambio. Por este motivo Freire (1993) nos alerta y realiza una dura crítica a cómo está configurado el mundo, al dictado de un sistema capitalista, en el que hay una brutal desigualdad entre los seres humanos, el reparto de la riqueza o a la discriminación:

Qué excelencia será esa que puede "convivir con más de mil millones de habitantes en el mundo en desarrollo que viven en la pobreza", por no decir en la miseria. Por no hablar tampoco de la casi indiferencia con que convive, con bolsones de pobreza y miseria en su propio cuerpo, el mundo desarrollado. Qué excelencia será esa que duerme en paz con la presencia de un sinnúmero de hombres y mujeres cuyo hogar es la calle, y todavía dice que es culpa de ellos y ellas estar en la calle. Qué excelencia será esa que poco o nada lucha contra las discriminaciones de sexo, de clase, de raza, como si negar lo diferente, humillarlo, ofenderlo, menospreciarlo, explotarlo, fuera un derecho de los individuos o de las clases, de las razas o de un sexo en posición de poder sobre otro. Qué excelencia será esa que registra tranquilamente en estadísticas los millones de niños que llegan al mundo y no se quedan, y cuando se quedan se van temprano, en la infancia todavía, y si son más resistentes y consiguen quedarse, pronto se despiden del mundo (FREIRE, 1993, p. 90).

Observamos a un Paulo Freire claramente posicionado en los planteamientos formulados desde la pedagogía crítica, reivindicando la legitimidad del sueño ético-político de la superación de las injusticias sociales y defendiendo una práctica educativa rigurosa en los contenidos y empapada en las posibilidades que tenemos los seres humanos de transformar el mundo. En coherencia con esto podemos afirmar que para Freire el principal valor y objetivo de la educación es la transformación de un mundo desigual e injusto en un mundo menos 
malvado y más amable para los seres humanos. Desde tales planteamientos (Freire, 1993) los educadores y educadoras debemos extraer todas las consecuencias de este valor y objetivo fundamental de la educación e intentar ser coherentes con el mismo (VERDEJA, 2018).

\section{Mensaje de esperanza: a pesar de que el cambio es difícil, es posible}

Para conseguir el cambio a un mundo mejor Freire (1993) señala que es imprescindible denunciar las injusticias que hoy en día existen pero, también menciona la necesidad de comprender que estamos a tiempo de cambiar las cosas y para ello debemos tener esperanza. La utopía y esperanza que manifiesta el educador brasileño hay que entenderlas como un proceso de construcción de nuestra propia historia y de las posibilidades que tenemos el conjunto de seres humanos de cambiar el rumbo de la historia:

La utopía implica esa denuncia y ese anuncio, pero no permite que se agote la tensión entre ambos en torno a la producción del futuro antes anunciado y ahora nuevo presente. La nueva experiencia de sueño se instaura en la misma medida en que la historia no se inmoviliza, no muere. Por el contrario, continúa (FREIRE, 1993, p. 87).

Freire (1997) se aproxima nuevamente a algunas cuestiones como la inconclusión del ser humano y su inserción en un permanente movimiento de búsqueda. Para ello hace hincapié en que los educadores y educadoras han de tener esperanza, virtud fundamental para alentar de que el cambio es posible, aunque reconoce que la educación tiene sus limites:

Ni la educación es una fuerza imbatible al servicio de la transformación de la sociedad, porque yo así lo quiera, ni tampoco la perpetuación del statu quo porque el dominante así lo decrete. El educador y la educadora críticos no pueden pensar que, a partir del curso que coordinan o del seminario que dirigen, pueden transformar al país. Pero pueden demostrar que es posible cambiar. Y esto refuerza en él o en ella la importancia de su tarea político-pedagógica (FREIRE, 1997, p.108).

Insiste Freire (2010) en que la educación necesariamente tiene que estar impregnada de sueños y utopía:

Para mí, aunque hoy se pregone que la educación ya no tiene nada que ver con el sueño, sino con el entrenamiento técnico de los educandos, sigue en pie la necesidad de que insistamos en los sueños y en la utopía. Las mujeres y los hombres nos transformaremos así en algo más que simples aparatos a ser entrenados o adiestrados; nos convertimos en seres de opción, de decisión, de intervención en el mundo, seres de responsabilidad (FREIRE, 2010, p. 141).

Cuando Freire (1994) apela a la esperanza no lo hace de una forma ingenua, ni tampoco entiende que los cambios llegarán de forma espontánea, implica, por lo tanto, un compromiso y pasar a la acción: social, cultural, política:

Sin embargo, según una visión auténticamente utópica, la esperanza, no quiere decir cruzarse de brazos y esperar. La espera solo es posible cuando, llenos de esperanza, procuramos alcanzar el futuro anunciado 
que nace en el marco de la denuncia por medio de la acción reflexiva (FREIRE, 1994, p.78).

Sin embargo, en el proceso de cambio, también existen algunas dificultades. Una de las grandes dificultades que plantea el educador tiene que ver con el riesgo de caer en el pesimismo, en la desesperanza. Freire (1997a, p. 119) plantea la dificultad de mantener la esperanza, sobre todo cuando las circunstancias son difíciles:

Es necesario mantener la esperanza incluso cuando la áspera realidad sugiere todo lo contrario. En esta situación, la lucha por la esperanza significa la denuncia sin medias palabras, de los desmanes, de los fraudes y las omisiones. Denunciándolos, despertamos en los otros y en nosotros mismos la necesidad y también el gusto por la esperanza.

Por todos estos motivos entendemos que Freire (2015) nos ha dejado un mensaje de esperanza y nos muestra las posibilidades que tenemos todas personas pero, en especial, las que nos dedicamos a la educación, a mantener vivo el sueño de que podemos cambiar el mundo. En una conversación con el editor de Presença Pedagógica, Neidson Rodrigues, decía lo siguiente:

Y si tengo un sueño, una utopía, debo luchar por ese sueño. ¿Se imagina un docente que no defienda, frente a sus alumnos, el sueño de una sociedad menos injusta y que no haga nada por la creación de una sociedad mas justa sólo porque su función específica es enseñar Biología... como si fuera posible enseñar biología, el fenómeno vital, sin tener en cuenta lo local? (FREIRE, 2015, p.116).

\section{La educación no lo puede cambiar todo, pero, algo puede hacer}

Sabemos que la práctica educativa es uno los temas de preocupación del educador brasileño. No en vano el propio Freire (1993, p. 104) reconocía la dificultad que entraña la tarea docente y lo expresaba así:

La práctica educativa implica además procesos, técnicas, fines, expectativas, deseos, frustraciones, la tensión permanente entre la teoría y la práctica, entre la libertad y la autoridad, cuya exacerbación, no importa cuál de ellas, no pude ser aceptada dentro de una perspectiva democrática, contraria tanto al autoritarismo cuanto a la permisividad.

Freire (2003) reflexiona sobre los saberes necesarios para la práctica educativo-crítica con base en una ética-pedagógica y en una visión del mundo cimentadas en el rigor, la investigación, la actitud crítica, el riesgo, la humildad, el buen juicio, la tolerancia, la alegría, la curiosidad, la competencia... entre otras virtudes, todas ellas, bañadas por la esperanza. Según Freire (2006, p. 199) la educación no es la única llave que abre las posibilidades de la transformación pero, reconoce que sin ella no es posible cambiar el rumbo de las cosas.

La educación no es la clave única para abrir la puerta de la transformación político-social de la sociedad. Ésta no es la única, pero sin ella no se hace nada. Esa complementación de mi discurso es fundamental para mostrar exactamente la relación dialéctica entre educación y sociedad, entre educación y transformación. 
Llegados a este punto vale la pena destacar la insistencia de Paulo Freire con respecto a los límites de la educación así como los límites de la práctica educativa, como nos recuerda en Gadotti (2007, p. 35):

La educación no lo es todo, solía decir. No podemos ser ingenuos si lo que queremos es tener una práctica educativa crítica y transformadora. Paulo Freire no puede ser acusado de ser un optimista ingenuo. No hay práctica educativa, como cualquiera de las otras prácticas, que escape a los límites. Límites ideológicos, epistemológicos, políticos, económicos, culturales [...]. Creo que la mejor afirmación para definir el alcance de la práctica educativa frente a los límites a los que ella se somete es la siguiente: sin poderlo todo, la práctica educativa puede logar algo.

Freire (2016) considera que, a pesar de las limitaciones que tiene la educación, podemos cambiar algunas cosas y esa es, precisamente, una de las mayores grandezas que nos brida y en ese sentido es totalmente consciente de los límites de la educación y es consciente de que por sí sola no logrará la transformación, pero, a pesar de sus limitaciones, algo puede hacer y por eso afirma: "Pero precisamente porque no lo puede todo, puede "algunas cosas", y en este poder algunas cosas residen su eficacia" (FREIRE, 2016, p. 43).

\section{Algunas reflexiones sobre el legado pedagógico de Paulo Freire}

Podemos decir que Freire ha contribuido al proceso de construcción de la historia y, como sujeto -por tanto activo-, ha participado en la construcción de la misma. Freire ha participado del momento y contexto socio-político en que le tocó vivir.

Entendiendo que el mundo es algo inacabado, y por tanto mejorable, analizando dicho contexto y la situación social, formuló propuestas educativas, pedagógicas, políticas, sociales, pensando y reflexionando acerca de las posibilidades que tenemos todas las personas, como sujetos en el proceso de construcción de la historia, para contribuir al cambio de esa historia y, por tanto, en la posibilidad que tenemos de construir nuestra propia historia.

Su pedagogía continúa siendo válida, no solo porque aún hay opresión en el mundo, sino porque responde a necesidades fundamentales de la educación en la escuela actual. La escuela y los sistemas educativos de hoy en día, ante la generalización de la información en la sociedad, se encuentran frente a nuevos y grandes desafíos. Algunos de ellos tienen que ver con las siguientes temáticas:

- Fruto de los procesos de globalización, las escuelas actuales son espacios educativos multiculturales, es decir, espacios en los que convive alumnado de diferentes culturas. La construcción de una escuela que reconozca y valore la diversidad cultural en todas sus dimensiones es uno de los retos más importantes del momento, es una necesidad vital. Es, además, un tema de justicia social. Se hace necesario transformar las escuelas y apostar por un modelo escuela y de currículo en el que tenga cabida la diversidad cultural del alumnado.

- Las escuelas actuales son escuelas multiculturales. Un modelo de escuela multicultural es una escuela permanente abierta al cambio y a la mejora. Ha de ser una escuela flexible, democrática, inclusiva y que reconozca la diferencia como un valor. Es una escuela que aprende y que -como señala Freire-, tiene en cuenta la identidad cultural de sus educandos. Sin embargo, la escuela actual, todavía no está abierta a reconocer la riqueza que nos brinda la diversidad cultural. La escuela y la diversidad presente en las aulas nos dan la oportunidad de aprender del contexto que nos rodea. Nos enseña Freire 
que la escuela debe ser humilde y aprender de sus relaciones con el contexto: "de ahí viene la necesidad de, profesándose democrática, ser realmente humilde, para poder reconocerse aprendiendo muchas veces con quien ni siquiera se ha escolarizado" (Freire, 2012, p. 122).

- Otro de los retos educativos del momento, tiene que ver con la necesidad de replantear el papel, tanto del profesorado como del alumnado, en los procesos de enseñanzaaprendizaje, sobre todo, en lo referente al proceso de construcción de conocimientos. Es necesario que el alumnado construya su propia visión del mundo -como insiste Freire-. Teniendo en cuenta esto, una de las principales funciones de los docentes implicaría ayudar conscientemente al alumnado a construir su propia y autónoma visión del mundo. Esto, cómo podemos inferir, es tremendamente complejo si todavía nuestros sistemas educativos siguen promoviendo un modelo de educación bancaria basado en la transmisión de conocimientos, algo que Freire critica duramente.

- Teniendo en cuenta lo anterior, otro de los retos educativos actuales tiene que ver con la preparación, tanto del profesorado como del alumnado, para una educación que tiene lugar en la sociedad de la información. Cada vez se hace más latente la necesidad de repensar las funciones de los docentes y su papel en la sociedad. Se hace igualmente necesario replantear el papel del alumnado en una sociedad compleja y cambiante en la que juegan un papel muy importante las tecnologías de la información y la comunicación. Es fundamental saber interpretar la información que nos rodea y que nos llega través de los diferentes medios de comunicación, como también lo es saber hacer una lectura y análisis crítico de la misma. Este proceso de alfabetización consiste, principalmente, en aprender a leer e interpretar de forma crítica el mundo y la realidad que nos rodea.

- Todo ello, en coherencia con Freire, tiene sentido porque, a pesar de que sabemos que la educación no lo puede cambiar todo, sí somos conscientes de que con la educación podemos contribuir a cambiar el mundo que nos rodea, es decir, estudiantes y docentes, como personas activas y por tanto un proceso de construcción del conocimiento y de nuestra propia historia, podemos cambiar el mundo que nos rodea.

- Para que el cambio sea posible, necesariamente, debemos hacer una lectura crítica del mundo. Dicha lectura crítica debe contribuir a tomar conciencia de la realidad en la que vivimos, pero, también -y quizás sea lo más difícil-, debe alentar las posibilidades de y transformación de la realidad. Freire ha dejado claro que todos los seres humanos tenemos en nuestras manos las posibilidades de la transformación. La lectura crítica del mundo, metafóricamente hablando, representa la mayor campaña de alfabetización de adultos y ese todavía es un reto pendiente.

El legado de Freire es amplio y diverso pero, hay una cuestión fundamental que, hoy en día, se convierte en una necesidad de primer orden: la necesidad de impulsar la lectura del mundo. Esta tarea, como nos señala Freire (1993), ha de ser desempeñada por docentes críticos, y necesariamente ha de ir acompañada de esperanza, sueños y utopía sin olvidar nunca que, tal transformación, aunque difícil, es posible. La educación necesita tanto de formación técnica, científica y profesional, como de sueños y utopía. Sin esperanza no es posible la transformación. Sin el sueño de una mejora colectiva no es posible la actividad transformadora.

Para Torres (2001) hay buenas razones por las cuales, en la pedagogía en la actualidad, podemos estar con Freire o contra Freire, pero no sin Freire. Como también nos recuerda el profesor Moacir Gadotti, actual director del Instituto Paulo Freire, en São Paulo, Brasil, no se le puede dar continuidad a Paulo Freire sin reinventarlo. Para esta tarea no designó a una persona o institución en particular. Esta tarea nos la dejó a todas las personas, es decir, a todos los seres humanos comprometidos con la causa de los oprimidos. 
Tomando como referencia a Paulo Freire y a los autores y autoras que hemos referenciado a lo largo de este trabajo, quien escribe estas líneas sí confía en la fuerza colectiva de los seres humanos para logar un mundo más justo e inspirado en unos principios de convivencia en dignidad para todos. Asimismo y como pedagoga, también confío en el potencial de la educación y en la responsabilidad que tenemos todas las personas pero, especialmente, las que en algunos momentos de nuestras vidas nos dedicamos a la tarea de enseñar, ya que a través de nuestra práctica educativa podemos hacer creíble que el cambio para mejorar, a pesar de que es difícil, no es imposible.

Somos, por otra parte, plenamente conscientes de que para que determinados cambios educativos se produzcan es necesario que exista activismo social y político -es decir, pedagógico- que lleve a decisiones de mejora educativa. En ese sentido, no debemos olvidarnos del potencial que tenemos todas las personas.

\section{Con la intención de concretar y poner de manifiesto la vigencia del pensamiento de Paulo Freire recogemos aquí algunas reflexiones finales:}

- Su obra cobra fuerza y gran relevancia en nuestros días, en nuestras sociedades y en los contextos educativos del momento. Percibimos que su legado pedagógico nos inspira a continuar con los cambios que el mundo necesita y percibimos una sensibilidad en el autor que nos impulsa a pensar en un mundo mejor, menos perverso y mas justo para todos los seres humanos. Esto nos lleva a pensar en los otros, en los que sufren, en las personas que son excluidas (del currículo, de las esferas sociales, culturales, políticas, económicas, etc.). Es necesario que se hable de los otros en las escuelas.

- Freire ha mostrado que existen formas diferentes de leer el mundo en el que vivimos. Eso representa, tal vez, la mas grandiosa e importante campaña de alfabetización de adultos, y continua siendo un reto pendiente en nuestras sociedades.

- Freire ha dejado claro que para entender el mundo y la diversidad de culturas que en el habitan, es imprescindible urgente y necesario cambiar el orden de las cosas. Por eso hace una dura crítica al neoliberalismo y a su ideología inmovilizante porque consigue "naturalizar" la desigualdad en cuanto que manifiesta que no hay nada que podamos hacer para cambiar las cosas. Por este motivo, una constante en su obra es llamar nuestra atención para recordarnos que la desigualdad no es natural. Es necesario agudizar nuestra capacidad crítica para sorprendernos y preguntarnos el por qué de las cosas.

- Freire hace una apuesta firme por la educación problematizadora que, desde una perspectiva crítica fomenta el diálogo, el debate y la reflexión acerca de los problemas actuales y se muestra como la alternativa a la "educación bancaria" que considera al alumnado y a la sociedad en general meros depositarios de contenidos anulando, así, la capacidad de las personas para pensar y reflexionar porque, además, fomenta una ideología fatalista e inmovilizante frente a los problemas del mundo.

- Desde la perspectiva de Freire un modelo de escuela multicultural ha de estar abierta a la comunidad educativa. Es un modelo de escuela democrática que además de estar abierta permanentemente a la realidad contextual de los educandos -como soñaba Freire- también debe estar dispuesta a aprender de sus relaciones con el contexto.

- La educación en contextos multiculturales conlleva necesariamente revisar la selección cultural de los contenidos que conforman el currículo común para hacer un diseño mas universal y representativo de todas las culturas y de la realidad social. Al mismo tiempo, en la selección de los contenidos curriculares -como recuerda Freire- es necesario preguntarse por cuestiones tales como: ¿a quién pertenece esa cultura? ¿a favor de quién está esa cultura? Cuestiones que nos servirán para comprender que, en definitiva, ninguna práctica educativa es neutra. 
- La transformación profunda de las escuelas es absolutamente necesaria. Ahora bien, para Freire, las escuelas no se transformarán si no entran en el proceso de cambio radical. Tal proceso no puede dejar de venir de fuera - realidad social, activismo, voluntad política de cambio, etc.- pero no puede dejar de partir de dentro -realidad y contexto social de los alumnos, metodología participativa, "agitación" democrática del docente, etc.-. Es la esencia de una escuela comprometida, de una escuela que aprende de la realidad contextual de sus educandos.

Paulo Freire fue una persona que tuvo una especial preocupación por el otro, por denunciar las injusticias y por mostrarnos que los seres humanos tenemos en nuestras manos las posibilidades del cambio y de la transformación. Para abordar todas estas cuestiones es necesario hacerlo a partir de la lectura crítica del mundo en el que vivimos y, para ello, es fundamental que nos preguntemos el porqué de las cosas que nos rodean, el porqué de las injusticias y de las diferencias entre ricos y pobres dado que, los seres humanos, tenemos posibilidades de cambiar tales injusticias y tenemos, por tanto, la posibilidad de transformar un mundo injusto para muchos en un mundo más amable para todos los seres humanos. La pedagogía de Freire propone una lectura crítica del mundo que no genere desesperanza, sino que permita ver las resistencias, las formas de salir adelante, de construcción de lo nuevo, las posibilidades permanentes que tenemos los seres humanos de reconstruir nuestra vida. Freire habló de la esperanza como una cuestión inherente a la práctica docente recordando que el cambio aunque difícil, es posible.

\section{Referencias}

BESALÚ, Xavier. Diversidad cultural y educación. Madrid: Síntesis, 2002.

FERNÁNDEZ ENGUITA, Mariano. La educación intercultural en la sociedad multicultural. Organización y Gestión Educativa, España, n. 6, p. 3-7, 2001.

FLECHA, José Ramón. El Freire que conocí. Cuadernos de Pedagogía, España, n. 259, p. 9091, 1997.

FREIRE, Paulo. Pedagogía del oprimido. 21. ed. Madrid: Siglo XXI, 1970

FREIRE, Paulo. Pedagogía de la Esperanza: un reencuentro con la pedagogía del oprimido. 7. ed. Madrid: Siglo XXI, 1993.

FREIRE, Paulo. La naturaleza política de la educación. Barcelona: Planeta De Agostini S.A. Siglo XXI, 1994.

FREIRE, Paulo. Pedagogía de la Autonomía. Saberes necesarios para la práctica educativa. 11. ed, Madrid: Siglo XXI, 1997.

FREIRE, Paulo. A la sombra de este árbol. 3. ed. Barcelona: El Roure Editorial, 1997a

FREIRE, Paulo. EI grito manso. Madrid: España. Siglo XXI, 2003.

FREIRE, Paulo. Pedagogía de la tolerancia. México: Centro de Cooperación Regional para la Educación de Adultos en América Latina y en el Caribe. CREFAL, 2006. 
FREIRE, Paulo. Pedagogía de la indignación. 3. ed. Madrid: Morata, 2010.

FREIRE, Paulo. Cartas a quien pretende enseñar. Madrid: Biblioteca Nueva, 2012.

FREIRE, Paulo. Paulo Freire. Pedagogía de los sueños posibles. Por qué docentes y alumnos necesitan reinventarse en cada momento de la historia. Argentina: Siglo XXI, 2015 .

FREIRE, Paulo. Paulo Freire. El Maestro sin Recetas: El desafío de enseñar en un mundo cambiante. Argentina: Siglo XXI, 2016.

GADOTTI, Moacir. La escuela y el maestro Paulo Freire y la pasión de enseñar. São Paulo. Brasil: Publisher Brasil, 2007.

GIROUX, Henry A. Una vida de lucha, compromiso y esperanza, Cuadernos de Pedagogía, España, n. 265, p. 42-52, 1998.

GIROUX, Henry. A. Los profesores como intelectuales transformativos. En: Giroux, H.A. Freire, P. y McLaren, P. Los profesores como intelectuales: hacia una pedagogía crítica del aprendizaje, Barcelona: Paidós, 1990, p. 171-178.

KAPLÚN, Mario. Una pedagogía de la comunicación. Madrid: La Torre, 1998.

KOHAN, Walter. Paulo Freire más que nunca. Una Biografía filosófica. Argentina: CLACSO. Consejo Latinoamericano de Ciencias Sociales, 2019.

LENS, José Luis. Paulo Freire: su praxis pedagógica como sistema. Instituto Paulo Freire (IPF) de San Paulo. UNCPBA. Buenos Aires: Yagüe, 2001.

PÉREZ TAPIAS, José Antonio. Educar desde la interculturalidad. Exigencias curriculares para el diálogo entre culturas. En Gimeno, J. (Comp.). Saberes e incertidumbres sobre el Currículum, Madrid: Morata, 2010, p. 149-161.

POSADA, Jorge Jairo. El Pensamiento de Paulo Freire y la construcción de propuestas pedagógicas y curriculares para la Interculturalidad. En ROCHA, Y. (Coord.). Tras las huellas de Paulo Freire, Managua, Nicaragua: IPADE/CEAAL, 2007, p. 123-146.

RIVAS-FLORES, José Ignacio y SVERDLICK, Ingrid. La persistencia en las desigualdades educativas. Desafíos para la igualdad en clave de la educación como derecho humano y social, Rizoma Freireano, España, n. 27, 2019

SANTOS-GÓMEZ, Marcos. Ideas filosóficas que fundamentan la pedagogía de Paulo Freire. Revista Iberoamericana de Educación, España, n. 46, p. 155-173, 2008.

TORRES, Carlos Alberto. La voz del biógrafo latinoamericano: una biografía intelectual. En M. Gadotti y C.A. Torres. (Coord.). Paulo Freire: una biobibliografía, España. Siglo XXI, 2001, p. 97-126.

TORRES, Rosa María. Los múltiples Paulo Freire. En Araujo Freire, A Ma (Coord.). La pedagogía de la liberación en Paulo Freire. Barcelona: GRAÓ, 2004, p. 193-203. 
TORRES SANTOMÉ, Jurjo. Diversidad cultural y contenidos escolares. Revista de Educación, España, n. 345, p. 83-110, 2008.

TORRES SANTOMÉ, Jurjo. La justicia curricular. El caballo de Troya de la cultura escolar. Madrid: Morata, 2011.

UNESCO. Directrices de la UNESCO sobre la educación intercultural. Sección de Educación para la Paz y los Derechos humanos. División de la Promoción de Educación de Calidad. Sector de Educación. Paris: Ediciones UNESCO, 2006.

VERDEJA, María. Ideas centrales del pensamiento pedagógico político de Paulo Freire: dimensiones de análisis, Revista Fuentes, España, v. 20, n. 1, p. 43-56, 2018 http://dx.doi.org/10.12795/revistafuentes. 2018.v20.i1.03

VERDEJA, María. El legado pedagógico de Paulo Freire: una pedagogía de la esperanza que nos invita a realizar una lectura crítica del mundo y soñar con las posibilidades de transformación en un mundo ético y profundamente solidario, Voces de la Educación, México, n. Extra 3, p. 50-67, 2020.

VERDEJA, María y GONZÁleZ RIAÑO, Xoxé Antón. Aportaciones de Paulo Freire a la educación intercultural. Un estudio de caso en la Educación Secundaria Obligatoria. Revista Iberoamericana de Educación, España, v. 76, n. 1, p. 143-168, 2018. https://doi.org/10.35362/rie7602854 